\title{
The Value of Transcranial Doppler Sonography in Hyperperfusion Syndrome after Carotid Artery Stenting: A Nationwide Prospective Study
}

\author{
Francisco Moniche, ${ }^{\mathrm{a}, \mathrm{b}}$ Irene Escudero-Martínez, ${ }^{\mathrm{a}, \mathrm{b}}$ Fernando Mancha, ${ }^{\mathrm{b}}$ Alejandro Tomasello, ${ }^{\mathrm{c}}$ \\ Marc Ribó, ${ }^{\mathrm{d}}$ Fernando Delgado-Acosta, ${ }^{\mathrm{e}}$ Juán José Ochoa, ${ }_{\mathrm{f}}^{\mathrm{f}}$ Joaquín Gil, ${ }^{\mathrm{g}}$ Rosario Gil, ${ }^{\mathrm{h}}$ \\ Montserrat González-Delgado, ${ }^{\mathrm{i}}$ Eduardo Murias, ${ }^{\mathrm{j}}$ Alain Luna, ${ }^{\mathrm{k}}$ Alberto Gil, ${ }^{\mathrm{l}}$ Sonia Mosteiro, ${ }^{\mathrm{m}}$ \\ María Dolores Fernández-Couto, ${ }^{\mathrm{n}}$ Luis Fernández de Alarcón, ${ }^{\mathrm{o}}{ }^{\mathrm{J}}$ osé M. Ramírez-Moreno, ${ }^{\mathrm{p}}$ \\ Joaquín Zamarro, ${ }^{\mathrm{q}}$ Guillermo Parrilla, ${ }^{\mathrm{q}}$ José L. Caniego, ${ }^{\mathrm{r}}$ Gustavo Zapata-Wainberg, ${ }^{\mathrm{s}}$ \\ Andrés González-Mandly, ${ }^{\mathrm{t}}$ José A. de las Heras, ${ }^{\mathrm{u}}$ Luis López-Mesonero, ${ }^{\mathrm{v}}$ Joaquín Ortega, ${ }^{\mathrm{w}}$ \\ Juan F. Arenillas, ${ }^{\mathrm{x}}$ Ernesto García, ${ }^{\mathrm{y}}$ Pedro P. Alcázar, ${ }^{\mathrm{y}}$ Elena Zapata-Arriaza, ${ }^{\mathrm{w}}$ \\ Asier de Albóniga-Chindurza, ${ }^{\mathrm{w}}$ Juan Antonio Cabezas, ${ }^{\mathrm{a}, \mathrm{b}}$ Pilar Algaba, ${ }^{\mathrm{b}}$ Aurelio Cayuela, ${ }^{\mathrm{z}}$ \\ Joan Montaner, ${ }^{\text {baa }}$ Alejandro González García ${ }^{\text {b,w }}$
}

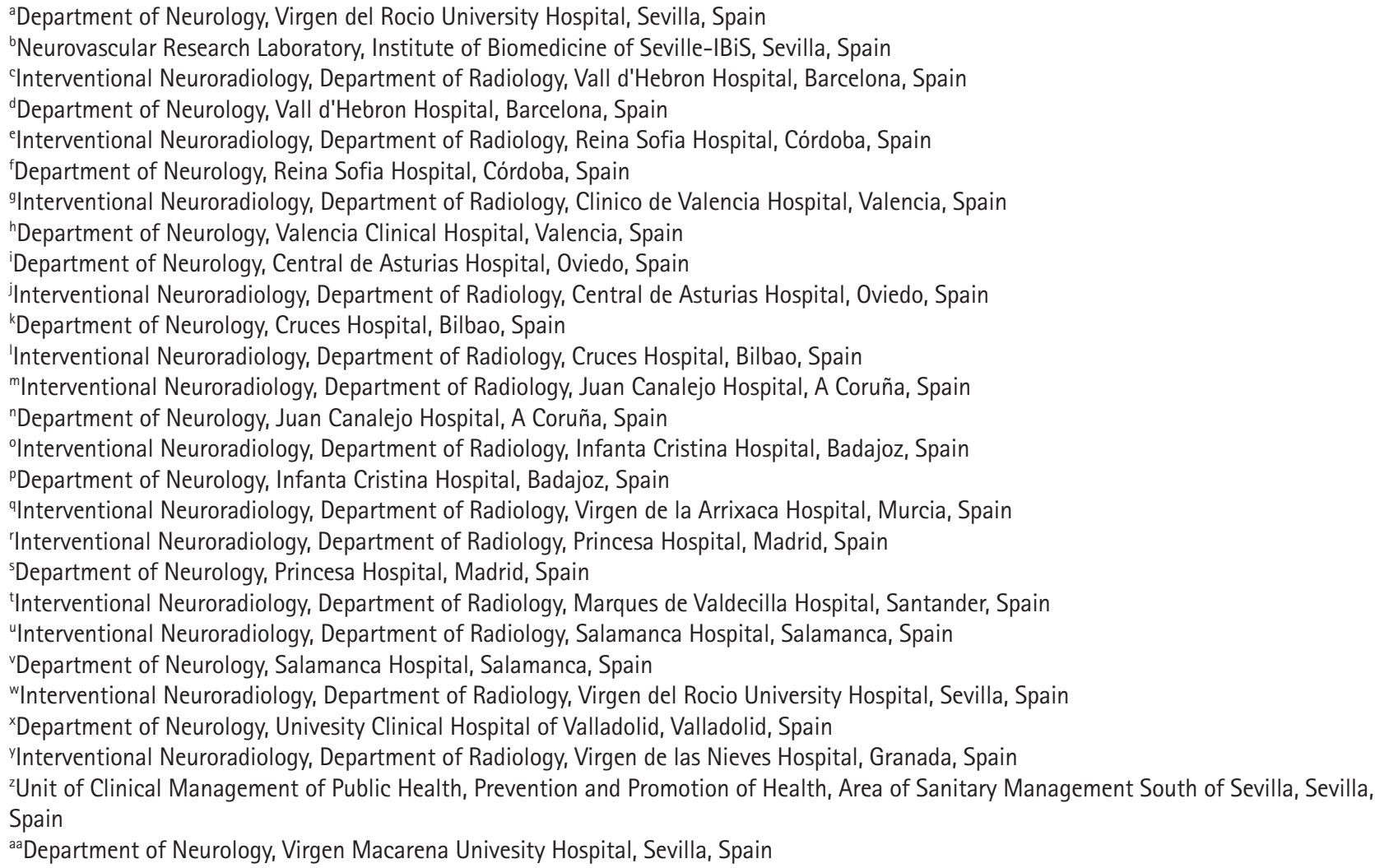




\section{Dear Sir:}

Cerebral hyperperfusion syndrome (CHS) is a life-threatening complication, defined as a combination of clinical features with evidence of hyperperfusion $>100 \% .{ }^{1}$ Hyperperfusion has been reported in 1\% to 3\% after carotid artery stenting (CAS). ${ }^{1}$ Although hyperperfusion evidence in those patients with the typical clinical syndrome seems to be a critical aspect of the CHS, the severity of the cerebral perfusion increase that is needed to develop the CHS is not clear. ${ }^{2}$ Definitions with different degrees of hyperperfusion have been used to diagnose CHS, although the most widely used is an increase in cerebral blood flow of more than 100\% compared with baseline values. ${ }^{1}$ The aim of the study was to validate prospectively the transcranial Doppler (TCD) criteria in diagnosis of CHS after CAS in a nationwide study.

This is a national prospective multicenter study. Inclusion criteria are detailed elsewhere. ${ }^{3}$ All patients underwent a baseline examination and follow-up was done up to 30 days with strict periprocedural blood pressure control. TCD was done before and 24 hours after CAS. In those patients with clinical-radiological CHS TCD was repeated at symptoms onset. Peak systolic velocity (PSV), pulsatility index (PI), and cerebrovascular reactivity (CVR) in middle cerebral artery (MCA) were measured. CHS was defined as (1) typical CHS clinical features with or without cerebral edema or intracerebral hemorrhage (ICH); (2) alternative diagnoses should be ruled out; and (3) evidence of hyperperfusion. Per protocol, there was no defined cut-off point for CHS diagnosis. CHS was classified as mild (only cephalea) or moderate-severe (impaired level of consciousness, seizures, neurological deficit, and/or ICH). We used univariate analysis for comparisons (SPSS version 25.0, IBM Co., Armonk, NY, USA; with $P<0.05$ as statistically significant). Area under the curve (AUC) was calculated to evaluate the accuracy of the increase of PSV for CHS diagnosis. The study was approved by the University Hospital Virgen del Rocio Ethics Committee. All patients signed informed consent forms.

Of 757 patients enrolled in the Hyperperfuslon Syndrome Post-carotid ANgloplasty And Stenting (HISPANIAS) study,

Table 1. Baseline patient characteristics

\begin{tabular}{|c|c|c|c|}
\hline Characteristic & Non-CHS $(n=537,96.2 \%)$ & CHS $(n=21,3.8 \%)$ & $P$ \\
\hline Men & $444(82.7)$ & $14(66.7)$ & 0.08 \\
\hline Age (yr) & 71 (63-78) & 76 (73.5-78) & 0.01 \\
\hline Previous TIA or stroke & $436(81.2)$ & 20 (95.2) & 0.14 \\
\hline Hypertension & $414(77.8)$ & $18(85.7)$ & 0.59 \\
\hline Diabetes & $205(38.5)$ & $12(57.1)$ & 0.08 \\
\hline Hyperlipidemia & $332(62.4)$ & $14(66.7)$ & 0.69 \\
\hline Ischemic cardiopathy & $153(28.9)$ & $4(19)$ & 0.33 \\
\hline Percentage of stenosis (\%) & $88(80-95)$ & $90(85-90)$ & 0.16 \\
\hline Symptomatic stenosis & 469 (81.4) & 20 (95.2) & 0.15 \\
\hline
\end{tabular}

Values are presented as number (\%) or median (interquartile range).

CHS, cerebral hyperperfusion syndrome; TIA, transient ischemic attack.

Table 2. TCD data comparison before and after CAS

\begin{tabular}{lccc}
\hline Variable & Non-CHS $(\mathrm{n}=537)$ & CHS $(\mathrm{n}=21)$ & \\
\hline Baseline TCD & & 36.8 & \\
Diminished vasoreactivity (\%) & 32.6 & $71.4(50.3-83.2)$ & 0.69 \\
PSV (cm/sec) & $74.0(62.3-89.9)$ & $0.80(0.6-1.2)$ & 0.23 \\
PI & $0.97(0.8-1.1)$ & & 0.23 \\
Post-CAS TCD & & $123.9(90.6-143.4)$ & 0.006 \\
PSV (cm/sec) & $95.0(76.1-118)$ & $1.30(1.1-1.6)$ & 0.043 \\
PI & $1.10(0.99-1.4)$ & $73.5(20-132.1)$ & $<0.001$ \\
Increase of PSV (\%) & $22.1(6.3-47.5)$ & $46.9(18.9-83.9)$ & 0.003 \\
Increase of PI (\%) & $16.9(0-40.2)$ & & \\
\hline
\end{tabular}

Values are presented as median (interquartile range).

TCD, transcranial Doppler; CAS, carotid artery stenting; CHS, cerebral hyperperfusion syndrome; PSV, peak systolic velocity; PI, pulsatility index. 


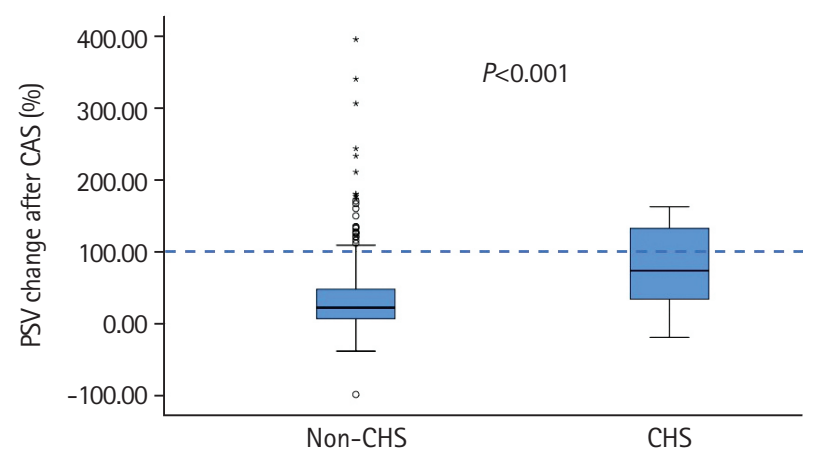

Figure 1. Comparison of peak systolic velocity (PSV) changes after carotid artery stenting (CAS) between the non-cerebral hyperperfusion syndrome (CHS) and CHS groups.

558 patients with complete TCD data were included in this study. Twenty-one patients (3.8\%) developed CHS (six mild CHS and 15 moderate-severe CHS). Median time from CAS to CHS was 21 hours (interquartile range, 6 to 42). Baseline characteristics are shown in Table 1. Of 21 patients with CHS, brain edema was detected in 43\%, ICH in 19\% and two CHS patients (9.5\%) died.

There was a marked increase in PSV and PI after CAS in CHS patients (Table 2). However, we detected no differences in CVR between the two groups. An increase of $>100 \%$ of TCD parameters was only detected in 10 patients (47.6\%) of the 21 CHS patients (Figure 1) with no positive relationship between the increase of PSV and CHS severity. However, an asymptomatic PSV increase of $>100 \%$ was detected in 34 (6.3\%) of 537 patients without clinical or radiological CHS changes.

Although the odds for developing CHS symptoms was 13.4 (95\% confidence interval $[\mathrm{Cl}], 5.3$ to $33.8 ; P<0.001$ ) in those patients with an increase of PSV of $>100 \%$, the cut-off point of an increase of $>100 \%$ in PSV as a criterion for CHS diagnosis had a high global accuracy (91.9\%), but had a sensitivity of $47.6 \%$ and specificity of $93.6 \%$, with a low positive predictive value $(22.7 \%)$. With a cut-off point of a $50 \%$ of increase, sensitivity improved to $66.7 \%$ with a $76.3 \%$ of specificity. AUC of ROC curve to evaluate accuracy of the increase of PSV for the CHS diagnosis was $0.742(95 \% \mathrm{Cl}, 0.61$ to $0.87 ; P<0.001)$.

Main finding of this study is that the "classical" criterion of evidence of hyperperfusion $>100 \%$ compared to baseline values for CHS diagnosis has a low sensitivity and may led to underdiagnose this severe complication. The present study is to the best of our knowledge, the biggest CHS study to date evaluating prospectively changes in brain perfusion after CAS. ${ }^{1,4}$ Other mechanisms than disturbed cerebrovascular au- toregulation need to be involved, as some patients developed a marked increase in Doppler values without symptoms and up to one third of the patients with clinical-radiological hyperperfusion syndrome had less than $50 \%$ of increase of preCAS values, even in those $\mathrm{CHS}$ patients with $\mathrm{ICH}$.

In one of the biggest series published, ${ }^{5}$ a low positive predictive value of increases of $>100 \%$ of PSV (8.0\%), with $66 \%$ of sensitivity was described, concluding that significant increases in MCA velocity did not identify patients at increased risk of suffering CHS. However, this cut-off point of hyperperfusion $>100 \%$ compared to baseline values for CHS diagnosis would have been underdiagnosed in our study about half of the patients that developed the clinical symptoms and neuroimaging CHS changes and had no evidence of alternative diagnosis.

We could classify TCD changes in four different patterns: (1) "benign hyperperfusion" with $>100 \%$ in PSV without symptoms (6.3\% in our series); (2) "life-threatening hyperperfusion or malignant hyperperfusion" with marked increase (i.e., >100\%) of PSV with CHS symptoms (2.0\%); (3) "non-hyperperfusion damage or reperfusion damage" with no or little increase in PSV but with CHS symptoms and radiological changes (1.8\%); and (4) "non-CHS patients" with no symptoms and no changes in TCD.

A limitation of this study is the time to perform the TCD post-CAS (i.e., 24 hours). If performed earlier it could have an impact on TCD data, although TCD was done in every CHS patient. Also, as mean flow velocity depends on both PSV value and end-diastolic velocity value, it depends more on the image quality and the variability of different operators. Therefore, we chose the most feasible measure (i.e., PSV) that is also widely accepted ${ }^{1}$ to decrease the possible variability between centers.

In conclusion, evidence of hyperperfusion $>100 \%$ as a cutoff point for CHS diagnosis, seems to be not valid for routine clinical practice. Our proposal is to include evidence of hyperperfusion as major supportive CHS criteria but with no cutoff point for diagnosis, as missing diagnosis would prevent an early treatment of this severe complication.

\section{References}

1. van Mook WN, Rennenberg RJ, Schurink GW, van Oostenbrugge RJ, Mess WH, Hofman PA, et al. Cerebral hyperperfusion syndrome. Lancet Neurol 2005;4:877-888.

2. Pennekamp CW, Tromp SC, Ackerstaff RG, Bots ML, Immink RV, Spiering $W_{1}$ et al. Prediction of cerebral hyperperfusion after carotid endarterectomy with transcranial Doppler. Eur J 
Vasc Endovasc Surg 2012;43:371-376.

3. González García A, Moniche F, Escudero-Martínez I, Mancha F, Tomasello A, Ribó M, et al. Clinical predictors of hyperperfusion syndrome following carotid stenting: results from a national prospective multicenter study. JACC Cardiovasc Interv 2019;12:873-882.

4. Galyfos G, Sianou A, Filis K. Cerebral hyperperfusion syndrome and intracranial hemorrhage after carotid endarterectomy or carotid stenting: a meta-analysis. J Neurol Sci 2017;381:7482.

5. Newman JE, Ali M, Sharpe R, Bown MJ, Sayers RD, Naylor $A R$. Changes in middle cerebral artery velocity after carotid endarterectomy do not identify patients at high-risk of suffering intracranial haemorrhage or stroke due to hyperperfusion syndrome. Eur J Vasc Endovasc Surg 2013;45:562-571.
Correspondence: Francisco Moniche

Stroke Unit, Department of Neurology, University Hospital Virgen del Rocio, Av. Manuel Siurot, S/n, 41013 Sevilla, Spain

Tel: +34-955012593

Fax: +34-955012597

E-mail:pmoniche@gmail.com

Received: March 4, 2020

Revised: April 22, 2020

Accepted: April 23, 2020

This study was supported by a Spanish grant from the Instituto de Salud Carlos III (ISCIII-FIS IP14/00971,2014-2017). The ITRIBIS project (Improving Translational Research Potential at the Institute of Biomedicine of Seville) has the registration number REGPOT-2013-1. Cooperative Cerebrovascular Disease Research Network (INVICTUS+)(RD16/0019/0015). Fernando Mancha is supported by a Rio Hortega contract. Francisco Moniche is PI of PI15/01197 and $\mathrm{PI} 18 / 01414$ grants.

This study was partially funded by Abbott (Chicago, IL, USA) and Grifols (Barcelona, Spain) but had no role in the design of the study, interpretation of the data or manuscript approval. 